\title{
A educação militar terrestre e a formação ética dos oficiais da Academia Militar das Agulhas Negras (1989-2018).
}

\section{Military education and the ethical formation of the Brazilian Military Academy (1989 - 2018)}

\author{
Fabio da Silva Pereira ${ }^{1 *}$
}

\begin{abstract}
RESUMO
O artigo objetiva apresentar uma breve análise sobre possíveis mudanças na estratégia educacional que impactaram maneira de ser e de pensar dos militares formados pela Academia Militar das Agulhas Negras (AMAN) ao longo dos últimos 30 anos. Para isso, a pesquisa contou com o acesso aos documentos internos do Exército Brasileiro (EB) e depoimentos tendo como o seu centro os antecedentes políticohistóricos que contribuíram para o planejamento e execução da construção de novos setores na AMAN em 1989, ano que estava ocorrendo algumas mudanças estruturais e curriculares no EB. O recorte conta a ação do Ministério do Exército na condução do que a elite castrense desejava preparar a sua jovem oficialidade formada no contexto da democracia brasileira.
\end{abstract}

Palavras-chave: Educação militar; Academia Militar das Agulhas Negras (AMAN); elite castrense.

\begin{abstract}
The article aims to present a brief analysis of possible changes in educational strategy that impacted the way of being and thinking of the soldiers trained by the Academia Militar das Agulhas Negras (AMAN) over the past 30 years. For this, the research had access to the internal documents of the Brazilian Army (EB) having as its center the political-historical background that contributed to the planning and execution of the construction of new sectors at AMAN in 1989, a year in which some structural and curricular changes in EB. The clipping tells the action of the Ministry of the Army in conducting what the military elite wanted to prepare its young officers formed in the context of Brazilian democracy.
\end{abstract}

Keywords: Military education; Academia Militar das Agulhas Negras (AMAN); military elite.

\footnotetext{
${ }^{1}$ Universidade Salgado de Oliveira.

*E-mail: fabio.pereira.historia@gmail.com
} 


\section{INTRODUÇÃO [Times New Roman, caixa alta, corpo 11, NÃO NUMERAR]}

A iniciativa deste estudo partiu de uma pesquisa bibliográfica e documental com foco nos documentos do antigo Ministério do Exército $^{2}$ e nos boletins internos da Academia Militar das Agulhas Negras (AMAN) ${ }^{3}$, de acordo com os princípios teóricos da história do tempo presente (HTP) e da História Oral. Embora os principais valores que norteiam a idealização desse perfil vigorem por força de lei desde $1980^{4}$, o intuito é elucidar aspectos ainda pouco conhecidos dos instrumentos e estratégias que alteraram o perfil militar dos oficiais que se formaram na $\mathrm{AMAN}^{5}$ com o foco no ano de 1989. Nesse ano, a AMAN praticamente dobrou a sua estrutura física e administrativa, com a inauguração de uma série de instalações permanentes: o Conjunto Principal II, a sede do Curso Avançado, e o Polígono de Tiro Guilherme Paraense, mais conhecido como a "Seção de Tiro".

Essas obras compunham parte de um portfólio estratégico do Exército - a Força Tarefa 90 (FT-90) - um conjunto de projetos que permitiram ao longo de quase trinta anos ampliar e oferecer o suporte para a formação de um militar mais voltado às atividades profissionais.

Na mesma época, outros fatores caminhavam em paralelo à conjuntura nacional de transição do governo Figueiredo para a democracia: para Martins Filho (2007, p. 10), no plano regional, a Guerra das Falklands / Malvinas, ocorrida em 1982, propiciou novos ensinamentos no campo militar e contribuiu para o processo de distensão entre Brasil e Argentina, que já se esboçava. Adicionalmente, a estrutura militar brasileira era bastante semelhante ao dos vizinhos argentinos ${ }^{6}$. Em consequência, os resultados político-militares ${ }^{7}$ do conflito no sul do continente

${ }^{2}$ O Ministério do Exército mudou para o Comando do Exército em 1999, com a criação do Ministério da Defesa.

${ }^{3}$ A Academia Militar das Agulhas Negras - AMAN, como estabelecimento de ensino superior militar, é herdeira da tradição bicentenária da formação do oficial subalterno e do capitão não aperfeiçoado da linha de ensino militar bélico do Exército Brasileiro, inicia a formação do chefe militar (BRASIL, 2017). O militar formado na AMAN é equiparado à formação universitária e recebe o diploma de bacharel em Ciências Militares, em consonância com a Lei de Ensino do Exército (BRASIL, 1999).

${ }^{4}$ Estatuto dos Militares (E1) - Lei n ${ }^{\circ}$ 6880, de 9 de dezembro de 1980 (BRASIL, 1980).

${ }^{5}$ Quando foi convocado pelo Ministro do Exército Leônidas Pires Gonçalves, o Coronel do Quadro de Engenheiros Militares (QEM) - formado pelo Instituto Militar de Engenharia - Cláudio Meirelles Santos manifestou parecer do ministro de que nada deveria ser feito sem um profundo estudo para, não apenas ampliar, mas também adequar a AMAN, para que os cadetes tivessem o mesmo padrão das modernas faculdades, com uso de computadores, vídeos etc. Que deveria ser dada uma solução que lhe possibilitasse ser, como a primeira, orgulho dos que por lá passaram, agregando valores para mais 50 anos de utilização e, ainda, mantendo uma lembrança de seus tempos de glória (VELLOSO, 2010).

${ }^{6}$ No Brasil de 1982 vigia ainda o governo militar, sob a presidência do general João Baptista Figueiredo. Guerras eram temas que naturalmente recebiam atenção especial do governo. Seu Exército era, até os anos 1970, o adversário tradicional nas hipóteses de emprego e jogos de guerra elaborados pelas escolas militares brasileiras. Seu equipamento e doutrina eram muito semelhantes ao do Exército brasileiro. A mesma inclinação para a guerra contrainsurgente, às expensas do preparo para a luta convencional, era encontrada. Parece lógico pensarmos o governo e o Exército brasileiros como atentos observadores do conflito (ALVES e CAMPOS, 2012, p. 258). 
motivaram a transformação do Exército Brasileiro (EB) na década de 1980 (ALVES e CAMPOS, 2012, p. 257). Nesse contexto, o general Walter Pires (1979-1985) e, sucessivamente o general Leônidas Pires Gonçalves (1985-1990), determinaram ao Estado-Maior do Exército (EME) que planejasse a reestruturação da Força, proporcionando a continuidade do projeto que estava em andamento desde os anos 1960 (PEDROSA, 2018), porém com um direcionamento focado no panorama dos anos 1980, onde a Guerra das Falklands / Malvinas teve uma influência importante. Dessa maneira, no ano de 1984 surgiu, no âmbito do Estado-Maior do Exército $(E M E)^{8}$, o Sistema de Planejamento do Exército - SIPLEX ${ }^{9}$. Esse plano perdura, com adaptações, até os dias de hoje ${ }^{10}$.

A formação profissional dos oficiais da linha de ensino militar bélico (LEMB) é o principal fio condutor da carreira dos futuros comandantes do Exército Brasileiro (EB). Nos últimos trinta anos o sistema educacional do EB, em especial o Departamento de Ensino e Pesquisa (DEP) ${ }^{11}$ lançou um grande desafio ao tentar avaliar de forma objetiva as atitudes e os valores militares revistos no Estatuto dos Militares. O ano de 1989 também trouxe contribuições para o campo teórico da História. Nesse mesmo ano surge a História do Tempo Presente (HTP) na França, onde Pieter Lagrou é um dos seus maiores colaboradores. Apesar do Instituto de História do Tempo Presente (IHTP) ter sido criado na década de 1970, Timothy Garton Ash publicou um livro chamado "The History of the present" (Ash, 1999) onde defende a prática de uma história recente, feita de entrevistas com os protagonistas e de full immersion nos acontecimentos (PÔRTO JÚNIOR, 2007, p. 32)

$\mathrm{Na}$ Academia Militar das Agulhas Negras (AMAN), essa diretriz refletiu-se, adicionalmente, na ampliação de sua estrutura física (obras iniciadas em 1987 e inauguradas em 1989), praticamente dobrando a capacidade de formação de oficiais, com o objetivo de, no futuro, fazer frente ao aumento de efetivos que se vislumbrava nos Projetos FT-2000 e FT-21. A AMAN é o estabelecimento de ensino militar responsável pela formação da maior parte da oficialidade de carreira do Exército Brasileiro. Ali são incutidos nos cadetes os principais valores da cultura organizacional da Força Terrestre, que serão desenvolvidos/cultivados ao

\footnotetext{
7 Por exemplo, a guerra revelou a impotência da Organização dos Estados Americanos (OEA) e do Tratado Interamericano de Assistência Recíproca (TIAR). Conforme demonstraram a inoperância desses instrumentos durante a guerra e o apoio ostensivo dos Estados Unidos ao seu aliado britânico, tais organizações eram funcionais somente quando respondiam aos interesses da superpotência do norte. A diplomacia brasileira ficou atenta a essa lição (CERVO e BUENO, 2002).

8 O Estado-Maior do Exército é o órgão de direção geral (ODG) da Força Terrestre, responsável por coordenar a ação de todos os setores do EB.

${ }^{9}$ O SIPLEx é o conjunto de medidas e ações do Estado, com ênfase na expressão militar, para a defesa do território, da soberania e dos interesses nacionais contra ameaças preponderantemente externas, potenciais ou manifestas (BRASIL, 1984).

${ }^{10}$ Segundo Kuhlmann (2007, p. 114) a possibilidade de adaptações já fazia parte do sistema, desde o início.

${ }^{11}$ Desde o ano de 2009, o DEP passou a se chamar Departamento de Educação e Cultura do Exército (DECEx).
} 
longo de toda a carreira do oficial. Seus cursos, desde 1964, possuem quatro anos de duração, dividindo-se em duas fases: Curso Básico ${ }^{12}$ e Cursos das Armas (são sete as especialidades ali conduzidas: Infantaria (Inf), Cavalaria (Cav), Artilharia (Art), Engenharia (Eng), Comunicações (Com), Material Bélico (MB) e Intendência (Int)). O ensino na AMAN contempla duas grandes áreas: Ensino Fundamental (disciplinas ditas "universitárias", nas áreas de Ciências Exatas e Ciências Humanas, para todos os cursos) e Ensino Profissional (disciplinas militares, comuns e específicas de cada curso). A fim de viabilizar a consecução da pesquisa em questão, foram pesquisados documentos internos da AMAN, tais como os boletins internos (BI) e os aditamentos do Corpo de Cadetes (CC) ao BI AMAN. No que diz respeito à metodologia, o presente trabalho está baseado nas contribuições de José D' Assunção Barros (2013), para a história oral, foram consultadas as obras de Ferreira e Amado (2006), Alberti (2013) e de Ciro Flamarion Cardoso e Ronaldo Vainfas (2012), de acordo com as seguintes classificações: quanto ao tipo de pesquisa (ou objetivo), trata-se de uma pesquisa descritiva, e, no que diz respeito aos procedimentos metodológicos, constitui-se num estudo de caso fundamentado em pesquisa bibliográfica e documental.

\section{A formação ética dos oficiais da linha de ensino militar bélico}

Após um ano de ensino preparatório na EsPCEx, uma vez aprovado, o aluno poderá ingressar a AMAN. Nesse sentido, a socialização dos oficiais da LEMB inicia antes mesmo da entrada nos portões acadêmicos. Os rígidos processos seletivos estabelecidos em editais fazem a verificação da situação social dos candidatos, através da comprovação de não possuir antecedentes criminais no cadastro nacional de segurança pública. Uma vez aprovado, o "ainda" candidato é submetido às noções básicas da cultura institucional durante o período de adaptação, de aproximadamente quinze dias ${ }^{13}$. Neste momento inicial, são distribuídos os manuais, dos quais se destacam o Estatuto dos Militares $^{14}$ (BRASIL, 1980), o Regulamento Interno dos Serviços Gerais ${ }^{15}$ (BRASIL, 2003) e o Regulamento Disciplinar do Exército ${ }^{16}$ (BRASIL, 2002).

12 De 1964 a 1976, o Curso Básico abrangia os dois primeiros anos; de 1977 a 1987 foi reduzido a um ano e, em 1988, retornou à conformação anterior de dois anos. Além de concentrar disciplinas ditas "básicas", tanto no Ensino Fundamental como no Profissional permite um período de convivência e conhecimento mútuos, objetivando um melhor relacionamento interpessoal futuro, visto que os cadetes serão mais à frente divididos em armas / serviços distintos.

13 Com exceção de alguns concursos esporádicos de ingresso imediato na AMAN (2004 e 2011), a entrada na LEMB se dá por meio da aprovação na EsPCEx. Nesse estabelecimento de ensino, o aluno aprende em um ano as noções básicas da profissão militar e faz contato com os integrantes da AMAN.

14 O presente Estatuto regula a situação, obrigações, deveres, direitos e prerrogativas dos membros das Forças Armadas (BRASIL, 1980).

${ }^{15} \mathrm{O}$ Regulamento Interno e dos Serviços Gerais ( $\mathrm{R}-1$ ou RISG) prescreve tudo que se relaciona com a vida interna e com os serviços gerais das unidades consideradas corpos de tropa, estabelecendo normas relativas às atribuições, às responsabilidades e ao exercício das funções de seus integrantes (BRASIL, 2003). 
O processo de socialização dos cadetes também envolve a aquisição de outros valores morais que deverão nortear suas ações não só ao longo de sua carreira, mas ao longo de sua vida, enquanto forem considerados militares, mesmo não estando mais no serviço ativo. A busca desses valores é orientada pela "ideia predominante" de honra, que deve acompanhar o militar e promover condutas que o levem a ser considerado digno do oficialato e da defesa da pátria. Em consonância, Celso Castro (2004) lista uma série de atributos que, em sua pesquisa, aparecem valorizados pelos cadetes e que, nessa perspectiva, são considerados complementares e necessários para o exercício da conduta honrosa, tais como seriedade, profissionalismo, competência, maturidade, disciplina e ordem. É interessante notar que esses valores devem resultar em "conduta moral e profissional irrepreensíveis", conforme estabelece os deveres militares relacionados com a ética (BRASIL, 1980). São, portanto, valores cuja busca é incentivada e que devem resultar em ações e atitudes regulamentadas por estatutos de aplicação interna à corporação. Além disso, o cultivo desses valores deve, também, estabelecer uma diferença comportamental evidente entre militares e civis, culminando com um afastamento do militar do mundo civil.

A percepção dos atributos militares como exemplos de verdadeiros valores éticos e morais, bem como o sacrifício pela pátria permeou um discurso do general Antônio Hamilton Martins Mourão por ocasião das comemorações do cinquentenário da morte do sargento Argemiro de Camargo, vítima de uma emboscada guerrilheira em 1965. Segundo Zatta e Vannini (2018), o discurso do general reafirma a visão militar sobre a "Redentora" (o movimento de 31 de março de 1964), além de deixar subentendida a ideia de que o Exército brasileiro salvou o país de uma ditadura comunista. Ainda, segundo esses autores, o ano de 2015 marcou a retomada do discurso institucional com posicionamento político favorável ao Regime Militar (1964-1985) (ZATTA e VANNINI, 2018, p. 209 - 210).

Além disso, o uso do uniforme e suas insígnias passam a figurar a rotina dos candidatos a aluno em uma escola militar, onde este é avaliado pelos três documentos ora citados. No caso do discente em um curso de formação da LEMB, os ornamentos criados revestem-se de uma atenção especial. Isto, porque alguns uniformes foram confeccionados especificamente para esse fim.

No primeiro ano da AMAN, o então cadete ${ }^{17}$ veste o uniforme histórico denominado de "Azulão". Adicionalmente, na semana do soldado, o cadete recebe o espadim, uma cópia

${ }^{16}$ O Regulamento Disciplinar do Exército (R-4 ou RDE) tem por finalidade especificar as transgressões disciplinares e estabelecer normas relativas a punições, comportamento militar das praças, recursos e recompensas (BRASIL, 2002).

${ }^{17} \mathrm{O}$ cadete, título de origem nobiliárquica, colocado em desuso no início do período republicano, ganhou novos contornos. Em 25 de agosto de 1931, foi criado pelo Coronel José Pessoa o "Corpo de Cadetes", em cerimônia à qual estiveram presentes, entre outras autoridades, o Presidente da República Getúlio Vargas (CASTRO, 2002, p. 42). 
reduzida da espada que o Duque de Caxias recebeu por seus serviços prestados ao Exército e ao Império do Brasil. A data é celebrada nas imediações do dia 25 de agosto, data de aniversário de Luís Alves de Lima e Silva ${ }^{18}$. Cabe destacar a atuação do Coronel José Pessoa Cavalcanti de Albuquerque na mudança no perfil da carreira da LEMB. Segundo Celso Castro:

\begin{abstract}
Com a criação do Corpo de Cadetes, o aluno matriculado na Escola passava a ser considerado parte de uma entidade coletiva [...]. O principal controle de que os novos preceitos disciplinares seriam seguidos deveria ser a consciência dos próprios cadetes, através da criação do que José Pessoa chamou, em sua autobiografia, de "um novo estado psicológico", que tornaria cada um "escravo da sua dignidade pessoal" [...]. Cada cadete era prisioneiro de si mesmo. E podemos afirmar, não havia prisão mais sólida. $\mathrm{O}$ objetivo principal era, portanto, atingir "a alma e o coração" dos jovens candidatos a oficial. Por isso, suas mais importantes iniciativas - e as mais duradouras foram no plano simbólico [...]. Em primeiro lugar, os uniformes dos cadetes foram mudados [...]. Foi solicitado o auxílio do artista José Washt Rodrigues para criar o novo plano de uniformes. Adotaram-se uniformes militares do Império, principalmente da campanha de 1852 contra Rosas $^{19}$ : barretina, cordões com palmatórias e borlas, charlateiras de palma e palmatória escarlate e emblema simbólico para a cobertura. A cor predominante passava a ser turquesa. O elemento mais importante passava a ser o espadim (CASTRO, 2002, p. 42-43).
\end{abstract}

Em consequência da atenção dada à criação de novos dispositivos e artefatos, o cadete passou a receber um tratamento mais rígido, sob um controle mais fechado. O sociólogo Erwin Goffman $^{20}$ afirma que a influência recíproca acontece quando os parceiros exercem sobre as suas ações respectivas, presenças físicas uns nos outros. Na educação militar, ocorre o processo de socialização mais intenso e longo de toda a formação técnica e superior.

O regime de internato, com mais de $10000^{21}$ (dez mil) horas de aula ou instrução de disciplinas profissionais, é dividido por meio de manobras militares e exercícios de campo. Este

\footnotetext{
${ }^{18}$ Luís Alves de Lima e Silva - o Duque de Caxias - é o patrono do Exército Brasileiro. Nascido em 25 de agosto de 1803, sua trajetória na carreira das armas é alvo de destaque perante os feitos militares e políticos dentro e fora do Império do Brasil. Como resultado, foi eleito com o título de Duque, segundo na escala nobiliárquica. A partir de 1923, a data de seu nascimento passou a ser comemorada, com maior relevância, até receber a alcunha de dia do Exército. Atualmente, o dia 25 de agosto é comemorado como o dia do Soldado, acompanhada de ritos específicos como formaturas militares, a cerimônia do juramento à bandeira nacional e o compromisso do espadim para os cadetes do primeiro ano da AMAN.

19 Juan Manuel de Rosas governou a Confederação Argentina entre 1835 e 1852, sendo derrotado pelas tropas lideradas por Caxias na Batalha de Monte Caseros, em território argentino, em 3 de fevereiro de 1852. Esse foi o único fato histórico em que as principais potências do continente sul-americano, Argentina e Brasil, se enfrentaram militarmente e seu resultado influenciou na escolha do uniforme dos cadetes da AMAN.

${ }^{20}$ No caso das instituições totais descritas por Erwin Goffman (1971), relacionadas à vida fechada e com horários definidos, é possível analisar alguns aspectos. Desde a hora de acordar, a "alvorada", até a hora de dormir, também chamado de "silêncio", é norma comum nas escolas de formação militar, em particular na AMAN, e suas congêneres, nas outras FFAA. Essas etapas são fases das atividades diárias programadas dentro de linhas estreitas, representando uma atividade conduzida no tempo predisposto para a próxima (GOFFMAN, 1971, p. 305).

${ }^{21}$ Currículo da Academia Militar das Agulhas Negras (BRASIL, 2016).
} 
longo período de, no mínimo, cinco anos ininterruptos, é considerado um sistema de isolamento comparado com uma "bolha" ou "um mundo à parte" (CASTRO, 1990). Mais tarde, o autor classificaria a Instituição castrense como "totalizante"22 (2007) ao invés de total, em referência ao estudo do canadense Erwin Goffman (1971), em atenção a detalhes colhidos através da observação participante desenvolvida entre os anos de 1987 e 1988, na AMAN. (Castro)

Quadro 1 - Diferenças entre a instituição total (Goffman) e a instituição totalizante

\begin{tabular}{|l|l|}
\hline \multicolumn{1}{|c|}{ Goffman (1971) } & \multicolumn{1}{c|}{ Castro (2007) } \\
\hline $\begin{array}{l}\text { Nas instituições totais, não se busca uma } \\
\text { "vitória cultural" sobre o internado, mas a } \\
\text { manutenção de uma tensão entre seu mundo } \\
\text { doméstico e o mundo institucional. Essa tensão } \\
\text { persistente é usada como "uma força estratégica } \\
\text { no controle de homens }\end{array}$ & $\begin{array}{l}\text { Numa academia militar busca-se justamente uma } \\
\text { a cultural" e não criar uma "tensão persistente": } \\
\text { academia é claramente vista como um local de }\end{array}$ \\
$\begin{array}{l}\text { Existe uma divisão rígida entre a equipe } \\
\text { dirigente e os internos. }\end{array}$ & $\begin{array}{l}\text { Inexiste uma divisão rígida entre "equipe dirigente" e } \\
\text { "internos" (inmates). Na cadeia de comando militar } \\
\text { não há uma separação da mesma natureza. }\end{array}$ \\
\hline $\begin{array}{l}\text { Trata principalmente dos estabelecimentos de a ser superado. } \\
\text { participação compulsória (prisões e } \\
\text { manicômios). }\end{array}$ & Numa academia militar, só fica quem quer. \\
\hline
\end{tabular}

Fonte: CASTRO (2007). Adaptação feita pelo autor.

O código de honra do cadete inicializa o militar no desenvolvimento de quatro deveres fundamentais: a verdade, a lealdade, a probidade e a responsabilidade (BRASIL, 2014, p. 24). Porém, o Vade-Mécum de Cerimonial Militar do Exército - Valores, Deveres e Ética Militares (BRASIL, 2002a) lista e categoriza somente dois desses quatro deveres, sendo eles, a lealdade e probidade.

O resultado é a fusão de inúmeros conceitos, que nem sempre são estritamente definidos e alguns até mesmo redundantes, os quais o cadete é submetido durante a formação de cinco anos. Como exemplo, observa-se na figura abaixo a repetição do item "Cumprimento dos deveres de cidadão" (Decoro da classe), sem que houvesse uma instrução sequer sobre a abrangência do tema. Outro fator está ligado a "Observância dos preceitos da ética militar" dentro do próprio diagrama instrucional, redundando à observação do diagrama como elo comunicativo.

Dessa forma, o item exercício da autoridade e a eficiência profissional carece de explanação situacional, deixando a questão estritamente aos manuais e regulamentos. Para atenuar as situações diversas os quais os cadetes são avaliados, o sistema de educação militar vem buscando contextualizar situações as quais o futuro oficial venha a enfrentar no exercício do comando de pequenas frações, sendo, ainda, um objetivo a ser alcançado, mesmo depois de

22 Castro refere-se à palavra "totalizante" para qualificar o ato de atribuir um caráter total (CASTRO, 2007, p. 5). O discurso aponta para um mundo diferenciado entre os "paisanos" e os "militares", em que os cadetes percebem-se em um processo "diferenciado" do que ocorre nos estabelecimentos de ensino superior civis. 
dois grandes projetos de ensino. A verdade e a responsabilidade estão inseridas no plano da ética militar, mas não possuem uma definição institucional específica. Além disso, o VadeMécum possui outros enunciados que carecem de significado objetivo, conforme a figura abaixo:

Figura 1 - Diagrama sobre a Ética Militar

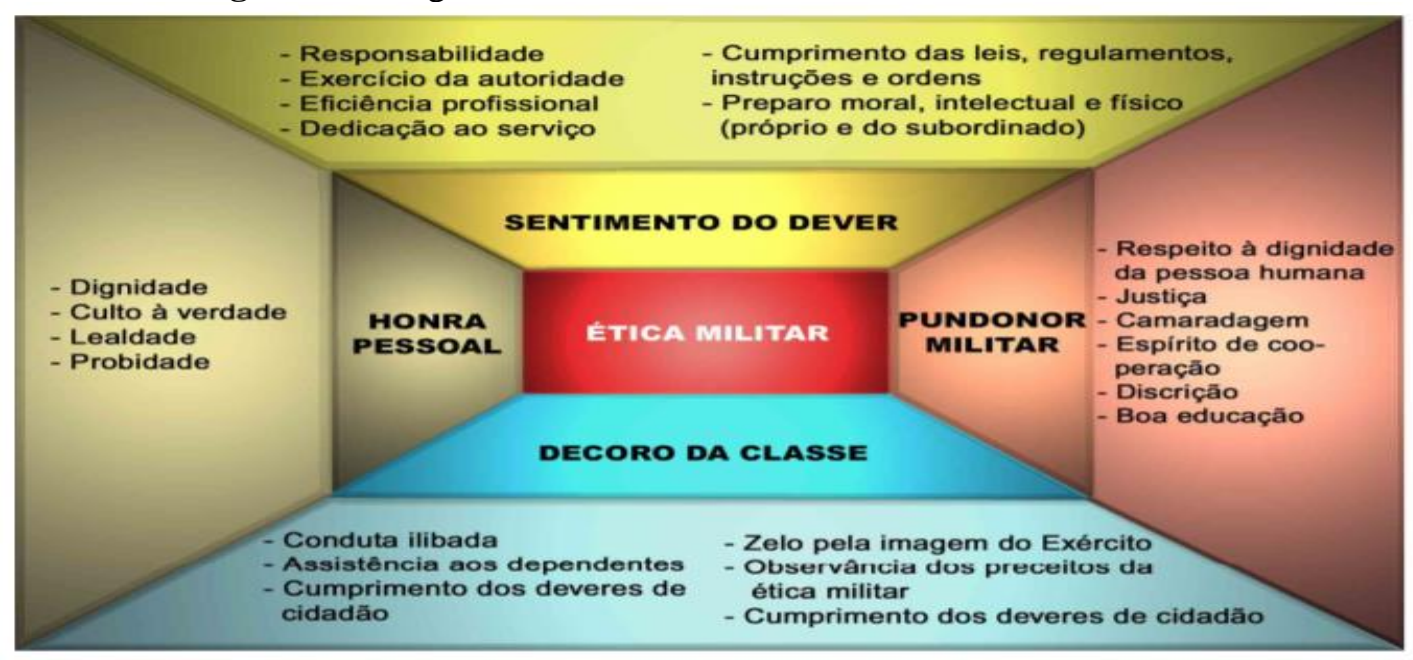

Fonte: BRASIL, 2002a, p. 10.

Os deveres adicionais listados, nesse documento, são o resultado da mudança gradual no "perfil do militar desejável" para atender às políticas públicas sob o contexto democrático. As políticas públicas são o campo de conhecimento que busca, ao mesmo tempo, "colocar a instituição em ação" e analisar essa ação e, quando for necessário propor mudanças (SOUZA, 2015, p. 111 - 112). O objetivo é interferir na percepção de relevância perante a sociedade e perante os comandantes militares, inspirando crédito e confiança para legitimar as lides castrenses diante das transformações do cenário político.

\section{CONSIDERAÇÕES FINAIS}

Os impactos gerados a partir da adoção de práticas voltadas às atividades de não-guerra e à promoção dos direitos humanos evidenciaram o diálogo interinstitucional para alterar o currículo escolar da AMAN. O entendimento de que a formação do oficial também envolve o preparo para as ações além da guerra entre estados nacionais contribuiu para a legitimação gradual do discurso de que os militares são preparados para a guerra e também para ações estatais de cunho estratégico.

As mudanças ocorreram à medida que o governo federal demandou cada vez mais ações subsidiárias ao Exército Brasileiro, sendo mais presentes na primeira metade dos anos 1990 e na primeira metade da década de 2010, momentos em que o Brasil estava sediando eventos de proporção mundial, como o encontro da ECO-1992, a sede da Copa das Confederações e da 
Copa do Mundo de futebol (2013-2014), e das Olimpíadas e Paraolimpíadas do Rio de Janeiro (2016).

Em paralelo, a sistemática de preparo do combatente terrestre estava sofrendo uma transformação. Em face da preparação focada nas três vertentes (cognitiva, psicomotora e atitudinal), não bastava somente ao cadete ter a rusticidade, ou seja, a resistência física diante das adversidades impostas pelo currículo profissional. Era necessário agora permear ao jovem oficial a ser formado a preparação para atuar em ambientes complexos, onde a necessidade de diálogo com civis é fundamental para o sucesso. Não que isso não tenha ocorrido em momentos anteriores, como na Segunda Guerra Mundial. Contudo, as demandas políticas e sociais nas operações militares aumentaram consideravelmente a partir da redemocratização no Brasil. 


\section{REFERÊNCIAS}

ALBERTI, V. Manual da História Oral, $3^{a}$ edição. Rio de Janeiro: Editora FGV, 2013.

ALVES, V. C; CAMPOS, M. T. A Guerra das Falklands/Malvinas e o Exército brasileiro. In: Tensões Mundiais, volume 8, n. 14. Fortaleza: UECE, 2012, p. 257 - 278. Disponível em: https://revistas.uece.br/index.php/tensoesmundiais/article/view/568. Acesso em: 16 jan. 2020.

ASH, T. G. History of the present: essays, sketches, and dispatches from Europe in the 1990's. Nova Iorque: Vintage Books, 1999.

BARROS, J, D. O campo da história: especialidades e abordagens ( $9^{\mathrm{a}}$ edição). Petrópolis: Vozes, 2013, 222 p.

BRASIL. Câmara dos Deputados. Lei $n^{\circ}$ 6880, de 9 de dezembro de 1980. Disponível em: http://www.planalto.gov.br/ccivil_03/leis/L6880.htm. Acesso em 20 ago. 2021.

BRASIL. Câmara dos Deputados. Lei $n^{\circ}$ 9786, de 8 de fevereiro de 1999. Disponível em: http://www.planalto.gov.br/ccivil_03/leis/L9786.htm . Acesso em 26 ago. 2021.

BRASIL. Ministério do Exército. Sistema de Planejamento do Exército. Brasília: Min Ex 1984.

BRASIL. Ministério do Exército. Estado-Maior do Exército. Relatório de Situação Geral da FT -90 no Triênio 86/87/88 (Confidencial). Brasília: Min Ex 1984.

BRASIL. Ministério do Exército. Centro de Comunicação Social do Exército (CComSEx). Noticiário do Exército nº 6722. Brasília: CComSEx, 15 mar. 1985.

BRASIL. Câmara dos Deputados. Decreto $n^{o}$ 4346, de 26 de agosto de 2002 Regulamento Disciplinar do Exército. Brasília: MD, 2002 Disponível em: http://www.planalto.gov.br/ccivil_03/decreto/2002/d4346.htm. Acesso em 22 mar. 2020.

BRASIL. Ministério da Defesa. Vade-Mécum de Cerimonial Militar do Exército Valores, Deveres e Ética Militares (VM 10). Brasília: SGEx 2002a. Disponível em: http://www.eb.mil.br/documents/10138/6563889/Vade+M\%C3\%A9cum+Valores.pdf/f 62fb2bb-b412-46fd-bda0-da5ad511c3f0. Acesso em 7. fev. 2021.

BRASIL. Ministério da Defesa. Regulamento Interno dos Serviços Gerais. Brasília: MD, 2003. Disponível em: https://bdex.eb.mil.br/jspui/handle/123456789/164. Acesso em 22 mar. 2020.

BRASIL. Câmara dos Deputados. Decreto $n^{\circ}$ 6703, de 18 de dezembro de 2008 Estratégia Nacional de Defesa (2008). Disponível em: http://www.planalto.gov.br/ccivil_03/_ato2007-2010/2008/decreto/d6703.htm. Acesso em: 7 jul. 2021. 
BRASIL. Ministério da Defesa. Portaria normativa $n^{\circ}$ 916/MD. Brasília: MD, 13 de junho de 2008a.

BRASIL. Ministério da Defesa. Exército Brasileiro. Academia Militar das Agulhas Negras. Academia Militar: dois séculos formando oficiais para o Exército. Resende: IPSIS gráfica e editora, 2011.

BRASIL. Ministério da Defesa. Secretaria de Ensino, Saúde e Desporto. Ofício $n^{o} 13854 / S E P E S D / D E P E C / D I E N S$ - MD. Brasília: MD, 14 de dezembro de 2011a.

BRASIL. Ministério da Defesa. Secretaria de Ensino, Saúde e Desporto. Programa elou curso de "Ética Profissional Militar". Brasília: MD, 14 de dezembro de 2011b.

BRASIL. Ministério da Defesa. Exército Brasileiro. Diretoria de Educação Superior Militar. Ofício $n^{o} 017$ - Seç Ens. 1 - CIRCULAR. Rio de Janeiro: DESMil, 23 de janeiro de 2012.

CERVO, A. L.; BUENO, C. História da política exterior do Brasil. Brasília: Editora UnB, 2002.

CARDOSO, C. F; VAINFAS, R. Novos domínios da história. Rio de Janeiro: Elsevier, $2012,335 \mathrm{p}$.

CASTRO. C. O espírito militar: Um estudo de antropologia social na Academia Militar das Agulhas Negras. Rio de Janeiro: Jorge Zahar Editor, 1990, 176 p.

CASTRO, C. A invenção do Exército Brasileiro. Petrópolis: Zahar, 2002.

CASTRO, C. Goffman e os militares: sobre o conceito de instituição total. In: Revistas UFRJ: Rio de Janeiro: UFRJ, $2007 . \quad$ Disponível em: https://revistas.ufrj.br/index.php/mp/article/download/33764/18928. Acesso em 18 ago. 2021.

FERREIRA, M. M; AMADO, J. Usos \& Abusos da História Oral, $8^{a}$ edição. Editora FGV, 2006.

GOFFMAN, E. As características de instituições totais. In A. Etzioni (Org.), Organizações complexas. São Paulo: Atlas, 1971.

KUHLMANN, P. R. L. Exército Brasileiro: estrutura militar e ordenamento político 1984 - 2007(tese de Doutorado). São Paulo: USP, 2007. Disponível em: http://www.teses.usp.br/teses/disponiveis/8/8131/tde-04032008-

114202/publico/TESE_PAULO_R_LOYOLLA_KUHLMANN.pdf. Acesso em: 10 jan. 2019.

MARTINS FILHO, João R . As Forças Armadas brasileiras no pós-guerra fria: o que mudou no pensamento militar? Ciclo de Palestras do Núcleo de Estudos Estratégicos do Programa de Pós-Graduação em Ciência Política da UFF. 2007. 
PEDROSA, F. V.G. Modernização e reestruturação do Exército Brasileiro (19601980). Tese de Doutorado em História. Rio de Janeiro: UFRJ, 2018.

PÔRTO JÚNIOR, G. (org). História do Tempo Presente. Bauru: Edusc, 2007, 360 p.

REMOND, René (org.). Por uma história política. Rio de Janeiro: UFRJ/FGV, 1996, $464 \mathrm{p}$.

VELLOSO, F. Breve relato sobre as obras de ampliação da AMAN - entrevista com o Coronel do Quadro de Engenheiros Militares (QEM) Claudio Meirelles Santos. Disponível em: http://www.aman62.com/a_aman_breve_obras.html. Acesso em $19 \mathrm{fev}$. 2019.

VIEIRA, G.. Uma grande evolução. In: Revista do Exército Brasileiro. V.136, 1999, p.5-6.

ZATTA, R; VANNINI, I. A. 1965 - 2015 - comemoração do cinquentenário da morte do tenente Camargo: um cerimonial militar fúnebre contemporâneo no Exército. In: RODRIGUES, F. S; ARIAS NETO, J. M. História Militar: entre o debate local e o nacional (Série Estudos Reunidos, volume 51). Jundiaí: Paco Editorial, 2018.

\section{Recebido em: 15/01/2022}

Aprovado em: 05/02/2022 